AIR WAR COLLEGE

AIR UNIVERSITY

\title{
BARE BASE EQUIPMENT AND SUPPORT OF THE EXPEDITIONARY AIR FORCE
}

by

Vic Wager III, Lt Col, USAF

A Professional Studies Paper submitted in

Partial Fulfillment of the Graduation Requirements

Advisor: Lt Col Marsha J. Kwolek

Maxwell AFB, Alabama

Distribution A: Approved for public release; distribution unlimited. 


\section{Report Documentation Page}

Form Approved OMB No. 0704-0188

Public reporting burden for the collection of information is estimated to average 1 hour per response, including the time for reviewing instructions, searching existing data sources, gathering and maintaining the data needed, and completing and reviewing the collection of information. Send comments regarding this burden estimate or any other aspect of this collection of information,

including suggestions for reducing this burden, to Washington Headquarters Services, Directorate for Information Operations and Reports, 1215 Jefferson Davis Highway, Suite 1204, Arlington

VA 22202-4302. Respondents should be aware that notwithstanding any other provision of law, no person shall be subject to a penalty for failing to comply with a collection of information if it

does not display a currently valid OMB control number.

\begin{tabular}{|c|c|c|}
\hline $\begin{array}{l}\text { 1. REPORT DATE } \\
\mathbf{2 0 0 3}\end{array}$ & $\begin{array}{l}\text { 2. REPORT TYPE } \\
\text { N/A }\end{array}$ & $\begin{array}{l}\text { 3. DATES COVERED } \\
\text { - }\end{array}$ \\
\hline \multirow{3}{*}{\multicolumn{2}{|c|}{$\begin{array}{l}\text { 4. TITLE AND SUBTITLE } \\
\text { Bare Base Equipment and Support of the Expeditionary Air Force }\end{array}$}} & 5a. CONTRACT NUMBER \\
\hline & & 5b. GRANT NUMBER \\
\hline & & 5c. PROGRAM ELEMENT NUMBER \\
\hline \multirow{3}{*}{\multicolumn{2}{|c|}{ 6. AUTHOR(S) }} & 5d. PROJECT NUMBER \\
\hline & & 5e. TASK NUMBER \\
\hline & & 5f. WORK UNIT NUMBER \\
\hline \multicolumn{2}{|c|}{$\begin{array}{l}\text { 7. PERFORMING ORGANIZATION NAME(S) AND ADDRESS(ES) } \\
\text { Air University Press Maxwell AFB, AL 36112-6615 }\end{array}$} & $\begin{array}{l}\text { 8. PERFORMING ORGANIZATION } \\
\text { REPORT NUMBER }\end{array}$ \\
\hline \multirow{2}{*}{\multicolumn{2}{|c|}{ 9. SPONSORING/MONITORING AGENCY NAME(S) AND ADDRESS(ES) }} & 10. SPONSOR/MONITOR'S ACRONYM(S) \\
\hline & & $\begin{array}{l}\text { 11. SPONSOR/MONITOR'S REPORT } \\
\text { NUMBER(S) }\end{array}$ \\
\hline
\end{tabular}

12. DISTRIBUTION/AVAILABILITY STATEMENT

Approved for public release, distribution unlimited

13. SUPPLEMENTARY NOTES

14. ABSTRACT

15. SUBJECT TERMS

16. SECURITY CLASSIFICATION OF:

\begin{tabular}{c|c|c}
$\begin{array}{c}\text { a. REPORT } \\
\text { unclassified }\end{array}$ & $\begin{array}{c}\text { b. ABSTRACT } \\
\text { unclassified }\end{array}$ & $\begin{array}{c}\text { c. THIS PAGE } \\
\text { unclassified }\end{array}$
\end{tabular}

17. LIMITATION OF ABSTRACT

$\mathbf{U U}$

\begin{tabular}{c|l}
$\begin{array}{c}\text { 18. NUMBER } \\
\text { OF PAGES } \\
\mathbf{3 4}\end{array}$ & 19a. NAME OF \\
& RESPONSIBLE PERSON \\
& \\
\hline
\end{tabular}




\section{Disclaimer}

The views expressed in this academic professional studies paper are those of the author and do not reflect the official policy or position of the US government or the Department of Defense. In accordance with Air Force Instruction 51-303, it is not copyrighted, but is the property of the United States government. 


\section{Table of Contents}

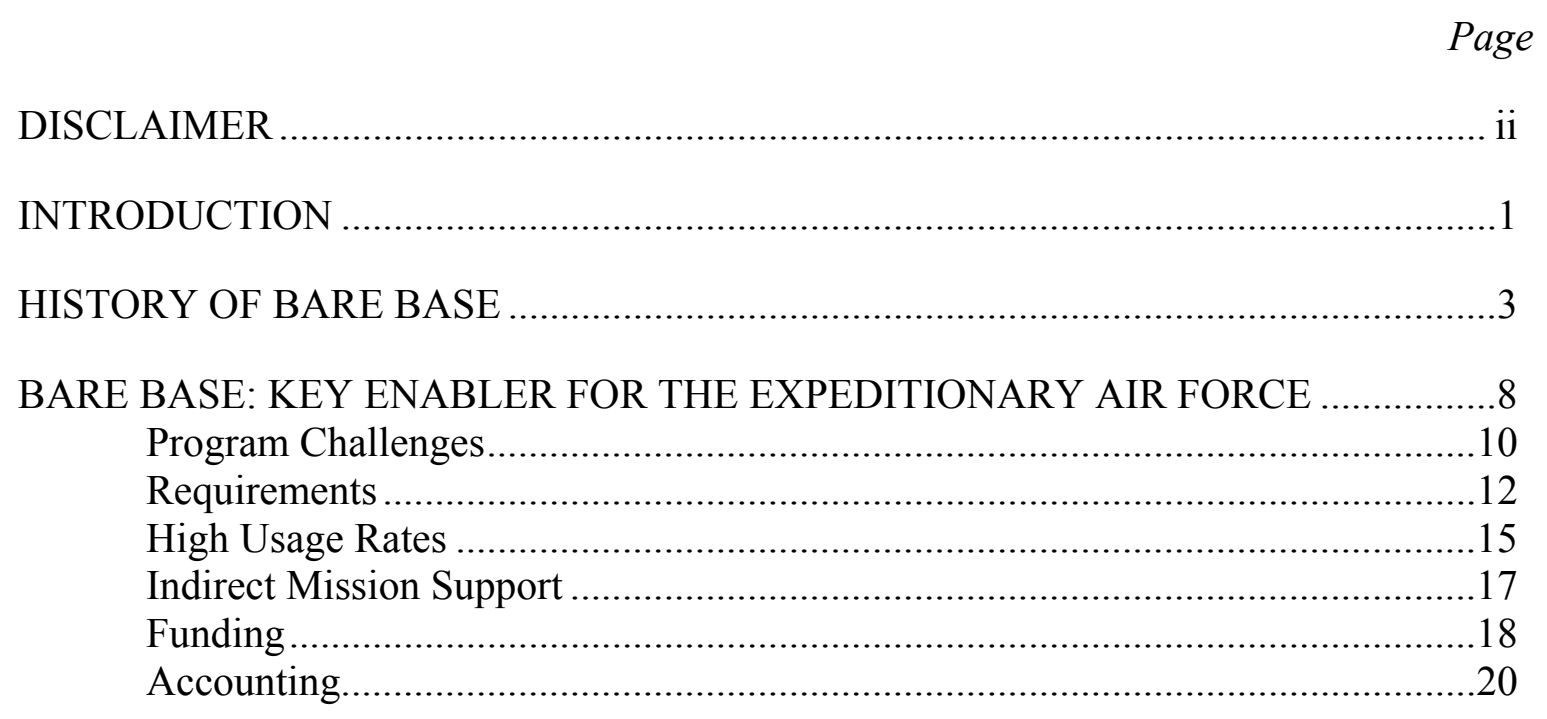

WILL THE BARE BASE PROGRAM BE THERE WHEN NEEDED? .......................23

WHAT DOES THE AIR FORCE NEED TO FIX? .................................................28

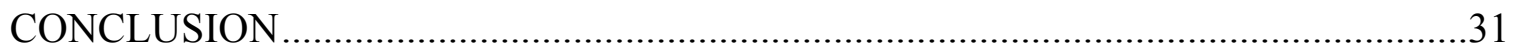

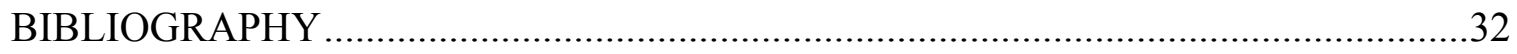




\section{Introduction}

The Air Force has a long history of developing expeditionary airpower that can rapidly deploy to provide support to the combatant commander. To provide this support, the Air Force Chief of Staff is developing force modules to provide improved capabilities for "rapidly opening an airfield, sizing ... mobility throughput, or generating a certain sortie level with fighters and bombers. These force modules could include initial airbase establishment, command and

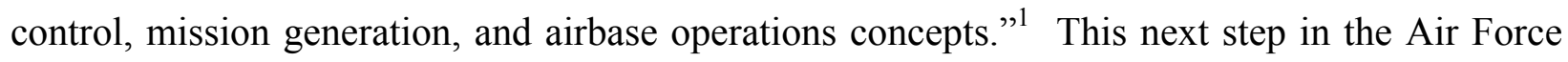
expeditionary journey will require a strong bare base program as the foundation for these force module packages. However, the current program is not capable of providing the support required by the Chief of Staff to support the combatant commanders.

The Air Force war reserve materiel (WRM) program consists of bare base assets, fueldistribution equipment and storage, munitions, afloat prepositioned capabilities, tank racks, adapters and pylons, prepositioned sites throughout the world ${ }^{2}$, special purpose and generalpurpose vehicles, and medical facilities and supplies. Base assets that include tents, shelters, generators, water purification, showers, and other housekeeping essentials. Thus, to analyze the entire program is beyond the scope of this paper. The foundation of the WRM program, base assets are the key to establishing forward airbases at bare base location and enabling the Air Force to rapidly deploy forces. Therefore, this paper focuses on bare base assets. It reviews the bare base program's history, evaluates its current challenges, and proposes solutions to improve support for today's expeditionary Air Force operations.

\section{Notes}

${ }^{1}$ Gen John P. Jumper, “Chief's Sight Picture: Corona Fall 2002,” 22 October 2002. 


\section{Notes}

${ }^{2}$ These are the principal worldwide WRM storage locations: Southwest Asia-Jordan, Bahrain, Qatar, Oman, Saudi Arabia; Pacific - Korea, Japan, Guam, Diego Garcia; EuropeEngland, Germany, Norway, Luxembourg; and CONUS—Holloman AFB. 


\section{History of Bare Base}

At the end of World War II, the military leadership realized that a highly mobile force was required to support and sustain the expanding military missions around the world. ${ }^{1}$ These missions put a premium on the Air Force having the capability to rapidly deploy and operate from any bare base location ${ }^{2}$ and gave birth to the current bare base concept of being able to establish an airbase anywhere in the world, with water and an airfield. Today, massive tent cities for 5,000 people can be established within days in austere locations throughout the world. These tent cities have assorted facilities with electrical and water systems, latrines and showers, sewage systems, kitchens, air-conditioning, and shops for transportation, civil engineering, services, aircraft maintenance, and operations. Additionally, airfield lighting, fuel storage and distribution systems, aircraft arresting, navigational aids, revetments, and warehouses, support flying operations for hundreds of combat aircraft.

The bare base equipment during World War II and the Korean conflict used existing buildings to the maximum extent. It consisted of canvas tents but no aircraft shelters and was all moved by truck convoys and trains. Setting up an operational base required a significant amount of time and effort. As the concept matured, the Air Force realized it needed to be able to establish an airbase in a shorter period of time. The bare base program needed to be "mobile, able to move quickly, pack up, and move as the ground forces advanced and retreated"3 but was hampered by the weight and size of the equipment. At the same time the Air Force was adjusting to the new requirements of the nuclear mission in the 1950s, the bare base program got a push to improve its ability to deploy worldwide. The Air Force created the composite air strike force (CASF) unit to establish the capability to be a worldwide, deployable nuclear response 
force. It developed the first mobility support kits, consisting of tents, field kitchens, medical facilities, power generators, cots, desks, and other equipment. However, the kits were not able to achieve the level of mobility needed, and work continued to improve the capability to move the CASF's heavy, bulky, and outdated equipment. ${ }^{4}$

In the 1960 s the trend toward lighter and more mobile bare base assets accelerated when Secretary of Defense McNamara castigated the Air Force for its delay in deploying forces to Vietnam, pending construction and completion of expensive permanent facilities. ${ }^{5}$ This criticism led to the creation of the Tactical Air Command's (TAC) Grey Eagle detachment which was directed to develop a suite of equipment consisting of four sets able to support 1,100 people each. Taking advantage of the speed and mobility of the C-130 aircraft, the TAC Grey Eagle support kits marked the beginning of greater reliance on airlift to move bare base equipment and added to the amount of tonnage that would need to be moved with limited airlift assets. This increased mobility came at a price, however, as it required $75 \mathrm{C}-130$ sorties to transport a single 1,100-person set. ${ }^{6}$ With several more innovations, the Air Force was able to reduce the size and weight of the Grey Eagle equipment by half, from 1,500,000 to 650, 000 pounds. But outsized and heavy equipment still had to be transported by surface modes. The heavy and outsized problem was never completely eliminated until advances in aircraft design produced the C-141, C-5, and C-17, which enabled all bare base equipment to be air transported, as long as it was designed to fit on these aircraft. Today moving a single 1100-person set still requires roughly 64 C-130 sorties. Thus, the issue has now shifted to one of movement priority, a problem equally as challenging. Methods employed to alleviate the airlift availability issue include prepositioning equipment in Southwest Asia, the Pacific, and Europe and putting bare base equipment on ships 
that can be moved to the desired location. All have had good results as long as the equipment is located close to or at the bare base location.

Despite the development and transportation challenges, the bare base program has provided the Air Force the ability to establish airbases anywhere it needs in the world in every conflict since Korea. The lessons learned during each conflict and, more importantly, the realization that the Air Force is not able to establish an airbase "anywhere" in the world has led to a refinement of the bare base concept. To be light and fast has required deploying to locations that have a basic airfield infrastructure. Thus, the bare base program has abandoned its "anywhere in the world" theme and adopted the more realistic approach of anywhere in the world that has "a runway, source of water, and nothing else." ${ }^{\prime 7}$ In summary, the development process that started with the composite air strike force using World War II equipment and was followed by TAC Grey Eagle has matured into the current inventory of Harvest Falcon (HF) and Harvest Eagle (HE) equipment sets.

The current bare base program consists of two main sets of equipment, HF and HE. The HF set, designed for longer duration flying, supports operations in Southwest Asia and consists of 1,100-person housekeeping, industrial operations, initial flight line, and follow-on flight line sets. The smaller HE equipment sets, intended for use in Europe and the Pacific, are comprised of 550-person-housekeeping utilities packages and 550-person cold weather sets. The Pacific Air Forces also maintain a smaller version of the HE equipment, designed to expand the billeting and feeding capacities at existing installations, which consists of 275-person housekeeping and 275person kitchen sets. ${ }^{8}$ The bare base program's long history of efforts to be more mobile continues today as the Air Force looks for ways to meet future expeditionary needs of the future. 
The $e$-Falcon and the Basic Expeditionary Airfield Resources (BEAR) are the next line of innovations to support the Air Force's need to be able to deploy even faster. The $e$-Falcon program is an attempt to reconfigure the existing bare base assets (HE and HF) to meet the Air and Space Expeditionary Force's (AEF) timing to establish a base within five days from the deployment order. ${ }^{9} \quad$ The objective of the e-Falcon program is to be able to accomplish its modifications at no cost and provide the needed equipment for the most likely bare base scenario. Essentially the $e$-Falcon concept of operations will be a very lean package up front, which will increase in capability as the deployment matures. ${ }^{10}$ Similarly, the BEAR concept is attempting to develop a basic configuration that will support the various force modules, but also include capabilities only needed with a specific weapon system or operation. For example, cold weather equipment would be added as required but would not be taken just because it is a part of the housekeeping set. ${ }^{11}$

Air Combat Command's Harvest Raptor program is examining advanced technologies to make the equipment lighter and more mobile. It exploits advances in technology, such as air beam structures, new power generation and distribution systems, and latrine waste disposal, that will help reduce deployment time by 75 percent and the labor hours to construct shelters by close to 85 percent. ${ }^{12}$ Furthermore, Congress is funding key research to improve the bare base program. In fiscal year (FY) 2002, Congress appropriated \$1.8 million for the Air Force Research Laboratory to conduct research in weapon systems logistics, deployed base systems technology, and force protection. ${ }^{13}$

\section{Notes}

${ }^{1}$ Capt Kenneth M. Weaver, “An Historical Analysis of the Air Force's Bare Base Concept and Equipment." Thesis. AFIT/GEM/LSR/895-18, Air Force Institute of Technology, Wright-Patterson AFB, Ohio, 28 December 1989, 6.

2 James R. Galluzzi, "The Bare Base Program--History and Analysis.” Research Study. Air Command and Staff College, Maxwell AFB, Alabama, May 1974, 8.

\footnotetext{
${ }^{3}$ Weaver, 6.
} 


\section{Notes}

${ }^{4}$ Weaver, 7.

${ }^{5}$ Galluzzi, 9.

${ }^{6}$ Weaver, 9.

${ }^{7}$ Weaver, 10.

${ }^{8}$ Air Force Handbook 10-222. "Guide to Bare base Assets," 1 December 1996, 5-7.

${ }^{9}$ Amatzia Feinberg, et al., "Supporting Expeditionary Aerospace Forces: Lessons from the Air War Over Serbia," RAND, MR-1263-AF, 2002, 36.

${ }^{10}$ Major Hai Vu, ACC/LGXW briefing. "Harvest Eagle--Harvest Falcon United States Air Force Bare Base [Online] Available: http://140.185.52.73/ilx/ilxx/wrm/wrmworkshop11.ppt, 22 June 1999, 17-18.

${ }^{11}$ Minutes. "Force Modules and BEAR Capability." Holloman AFB, NM, 19-21 November $2002,1-12$.

12 “AFRL/ML Success Story: Inflatable Structures Can Reduce Logistics and Setup times for Bare-Base Operations" [Online] Available: http://www.ml.afrl.af.mil/stories/mlq-01124.html, 1-3.

${ }^{13}$ Headquarters United States Air Force. "RDTE \& E Budget Item Justification Sheet (R2A Exhibit): 03-Advanced Technology Development, 0603205F Flight Vehicle Technology," February 2002, 5 . 


\section{Bare Base: Key Enabler for the Expeditionary Air Force}

As the Air Force prepares for the $21^{\text {st }}$ century, the need for a mobile air force ready to deploy where needed has been reinforced by two Chiefs of Staff. According to General Michael E. Ryan, an expeditionary aerospace force means: "having a force that is light, lean, and lethal ... It means operating out of any location with a smaller footprint, which requires less support and fewer lives put in danger." 1 The current Chief of Staff, in a statement to the $106^{\text {th }}$ Congress, observed: "Our primary goal is to provide rapid and responsive aerospace forces across the spectrum of conflict ... we must be ready to deploy anywhere on the globe. For this, our forces need to be as light and lean as possible."

The requirement to be mobile and ready to fight anywhere in the world was recently demonstrated in Operation Noble Anvil and Operation Enduring Freedom (OEF). RAND, in its book on the conflict in Serbia, provides a comprehensive view of the magnitude of the expeditionary effort required for the Air Force today.

More than 43 units operated out of 25 locations; more than 22,000 people deployed, with more than 14,000 arriving by air to augment the more than 21,000 already in theater; 11,000 logistics personnel, including more than 10,000 maintainers, supported the effort; 530 aircraft flew more than 29,000 sorties, including more than 5,800 by Air Mobility Command, for a total of 86,367 flight hours. ${ }^{3}$

In the first 100 days of OEF, there were 12,000 people deployed to 14 different locations. Two hundred aircraft flew 11,000 sorties, airlifted approximately 5,000 tons of munitions, and sealifted 3,000 tons from the continental United States (CONUS) and 8,000 tons from prepositioned ships. Also, the Air Force flew nearly 2,000 strategic lift missions, and 24 tactical airlift aircraft flew 2,700 tactical lift sorties. This level of effort requires bare base assets as the foundation for success. Without the basic airbase infrastructure provided by the bare base 
program, an operation of this magnitude would not be possible in the same amount of time. In his 22 October 2002 Chief's Sight Picture, General Jumper noted:

The Air Force must transition to the next level in our expeditionary journey and fully explain to the Combatant Commanders how we present forces .... We will do this by developing force modules that very roughly size a force package to a task, thus enabling a systematic presentation of our capabilities, rapidly opening an airfield, sizing a specific level of mobility throughput, or generating a certain sortie level with fighters and bombers. These force modules could include initial airbase establishment, command and control, mission generation, and airbase operations concepts ... ${ }^{4}$

The current AEF goal, to have an airbase up and running at any bare base location in the world five days after the deployment starts, constitutes a challenge that the Air Force has never been able to overcome. ${ }^{5}$ For example, for various reasons not a single OEF location was able to achieve this goal. Even with some bases in the region having US forces present, and others possessing little more than a runway, the Air Force struggled to become operational quickly. Diego Garcia was operational in 17 days, while Jacobabad, Pakistan, took 73 days. At Jacobabad, 73 days were needed for site preparation, establishment of force protections, repair to deteriorating parking ramps, communications set up, and building of munitions pads and a tent city. ${ }^{6}$

To bed down forces, OEF utilized, 1,564 civil engineering people at nine austere locations. Construction projects included runway repair, ramp construction, tent cities, maintenance areas, and aircraft shelters. Of the 83,000 tons of cargo moved to support OEF, 70,000 tons were required to set up and sustain the forward operating airbases. ${ }^{7}$ This support included civil engineering equipment, tentage, shower and shave units, water-purification systems, fuels mobility support equipment (FMSE) (e.g., bladders, hoses, and pumps), and munitions. These efforts would have not been possible without the bare base program, which enables the Air Force to set up an airbase rapidly almost anywhere in the world. 
RAND studies emphasize that the AEF concept "depends on the agility and responsiveness of the support system to provide the resources needed to conduct operations in areas of the world. The effectiveness and efficiency of that support system are in turn, ... critically dependent on strategic support decisions such as infrastructure investment in forward operating locations, forward support locations, and transportation." 8 The agility and responsiveness of the support are even more critical as the Air Force moves to the force module concept. However, the recent studies have not included an in-depth look at the core component that enables the entire system to operate--bare base assets. There has been little research to determine if the bare base program is capable of supporting future operations. For instance, during OEF bare base equipment was not up to standards:

"The sites required housekeeping sets, industrial sets, FMSE, munitions, and other equipment from the WRM assets. At the end of the deployment phase of OEF, of the 28 mission-ready Harvest Falcon sets, 15 complete sets were deployed, 11 sets were missing several components, and/or needed maintenance to be ready for use, and 2 mission-ready sets were held in reserve. The 11 sets were primarily missing similar assets like power distribution units, lighting units, and expandable common-use shelters." 9

This paper will now examine the bare base deficiencies that require immediate attention to ensure the program can provide the support needed and expected.

\section{Program Challenges}

The program has several challenges it must overcome, with the most important concerning the status of the equipment, requirements, high usage rates, indirect use, and finally, funding. This section will examine each of these issues in depth.

Mission Readiness 
Figure 1 is an overall summary of the Air Force bare base requirements and the missionready sets available to support deployment operations just prior to OEF. With four of six categories of HF and HE sets below the 50 percent mission-ready level, the Air Force's ability to support expeditionary operations is obviously at risk.

\begin{tabular}{|c|c|c|c|c|c|c|}
\hline & \multicolumn{3}{|c|}{ Harvest Falcon } & \multicolumn{3}{|c|}{ Harvest Eagle } \\
\hline Type of Set & Requirement & Miss & $\begin{array}{l}\text { ready and } \\
\text { rcent }\end{array}$ & Requirement & Miss & $\begin{array}{l}\text { eady and } \\
\text { sent }\end{array}$ \\
\hline Housekeeping & 50 & 23 & $(46 \%)$ & 24 & 16 & $(66 \%)$ \\
\hline Industrial & 15 & 4 & $(27 \%)$ & $\mathrm{n} / \mathrm{a}$ & $\mathrm{n} / \mathrm{a}$ & \\
\hline Flight line & 25 & 6 & $(24 \%)$ & 15 & 6 & $(40 \%)$ \\
\hline
\end{tabular}

Figure 1. Status of Bare Base Equipment as of May $2001^{10}$

The HE requirement to maintain 24 housekeeping sets came closest to being achieved, with 16 mission-ready sets available as of May 2001. More disturbing, however is the fact that during the 1991 to 2001 period, the average number of mission-ready HF housekeeping sets averaged 13.5. Moreover, the critical elements to support the AEF, industrial and flight line sets are at 27 percent and 24 percent mission-ready for the HF program. The HE program is in a little better shape and seems to be more stable than the HF program. It maintained an average of 16 mission-ready housekeeping sets between 1991 and 2001 but was not able to get more than 20 sets mission-ready in any year during that same period. ${ }^{11}$ Also, the flight line sets consistently remained inadequate to meet requirements. As of December 2002, the bare base program had only two mission-ready HF housekeeping sets, ${ }^{12}$ a number distinctly inadequate, particularly in light of anticipated operations in Iraq.

One factor in the inability to build complete sets in both programs can be attributed to the difficulty in replacing several single items in sufficient quantities to bring a set up to missionready status. For example, in the HF area of power generation, the program is short 5,497 of the 6,680 required power distribution panels, which are budgeted for in the FY03 Air Force Program 
Objective Memorandum (POM). ${ }^{13}$ To obtain the required HF sets shown in Figure 1 , the program must have 6,680 panels. Additionally, the program needs 1,974 more environmental control units (ECU), ${ }^{14}$ which are programmed in the FY06 budget. ${ }^{15}$ There are several required assets that are programmed in the FY02-FY06 budget, and until these assets can be purchased, the mission-ready rates will change little. Similarly, the HE program has none of the power distribution panels it needs and is using a work-around to overcome the shortfall. The projected get-well date for all 1,704 panels is FY07. Likewise, the program is short 1,159 ECUs of the 1,896 needed, with an anticipated get-well date of FY08. ${ }^{16}$

HF and HE programs, the sole bare base infrastructure assets in the Air Force, have had a poor mission-ready status since the end of the Gulf War. Historically, mission-ready rates indicate that bare base assets have about 50 percent capability or less in most areas. However, these rates are based on requirements that have been in effect for many years and have recently come under criticism.

\section{Requirements}

The General Accounting Office (GAO), in a report to the Senate Subcommittee on Readiness, questioned Air Force bare base requirements, claiming that they could lead to overstatements of need and readiness. "The Air Force does not have precise requirements established for its prepositioned bare base and vehicle programs. Without this foundation, it is impossible to reliably assess the impact of reported shortfalls and maintenance concerns and, thus, the overall readiness of the program." ${ }^{17}$ The report recommends that Air Force bare base support plans enumerate the requirements for all functions needed to support a proposed airbase and include detailed analysis. As of August 1998, none of the 18 support plans required for the Central Command (CENTCOM) area of responsibility had been completed. ${ }^{18}$ The GAO only 
investigated the CENTCOM region and made no mention of the other combatant commanders' areas of responsibility. However, the majority of the bare base assets are in the CENTCOM region, which has the lowest mission-readiness rates of all the Air Force commands. As of May 2001, HF had a stated requirement for 90 sets (housekeeping, industrial, and flight line), with only 33 mission-ready, while the HE required 39 sets (housekeeping and flight line), with 22 mission-ready. Requirements for the HF sets were established more than 20 years ago and have not changed substantially since. ${ }^{19}$ Also, the essential planning documents have not been completed to ensure that requirements are valid. Though the GAO's assertion of invalid requirements is indeed correct, accurately assessing the actual health and needs of the program poses genuine challenges.

The AF/ILS March 1998 Program Management Directive for mobile bare base equipment establishes the requirement for the program to support two major theater wars. The methodology used to determine the amount of equipment could not be ascertained in any of the documents reviewed. This criticism is not new. In 1970 the Air Force Audit Agency discovered, "The methodology used to establish authorizations ... was not consistent with the methodology to establish program requirements. As a result ... authorizations were overstated by a total amount which could range from $\$ 511,000$ to $\$ 1,013,000 ., 20$ According to the report, the program objective sized the billeting for 4,500 for each base augmentation support set (early version of the modern housekeeping set), but the sets were designed for 4,730 people. The audit concluded that the increase over the program objective number could not be explained. ${ }^{21}$ The methodology to develop the program requirements seems to be done in a less- than-scientific way and generally relies on experts to determine the numbers. For instance, a workshop held in November 2002 to build the initial estimates of the BEAR to support the Chief of Staff's force 
module concept recommended building and testing a 150-person AEF package which represents an additional size requirement for the bare base program. No methodology, other than attendees' suggestions on package size, was identified in the workshop minutes. Furthermore, none of the proposed packages for the BEAR concept are close to the HF housekeeping set sizes that account for the majority of sets in the inventory, which are designed for 1,100 people. ${ }^{22}$

Another issue that the BEAR concept will face is its ability to compete in the Air Force budget process. The current bare base budget justification is based on purchasing and maintaining 50 housekeeping sets out to FY09. The BEAR concept, with its new requirements tends to dilute the justification for the 1,100-person housekeeping set by adding yet another number to the constantly changing bare base requirements figure. Why must the Air Force keep 50 housekeeping sets but also have the capability to acquire and maintain additional BEAR sets? 


\section{High Usage Rates}

The continual rise of assets by various operations and exercises during the period since the end of the two Gulf War has resulted in a constant fluctuation of bare base mission-ready rates. A graphic example of how events between 1991 and 2002 impacted the mission-ready status of

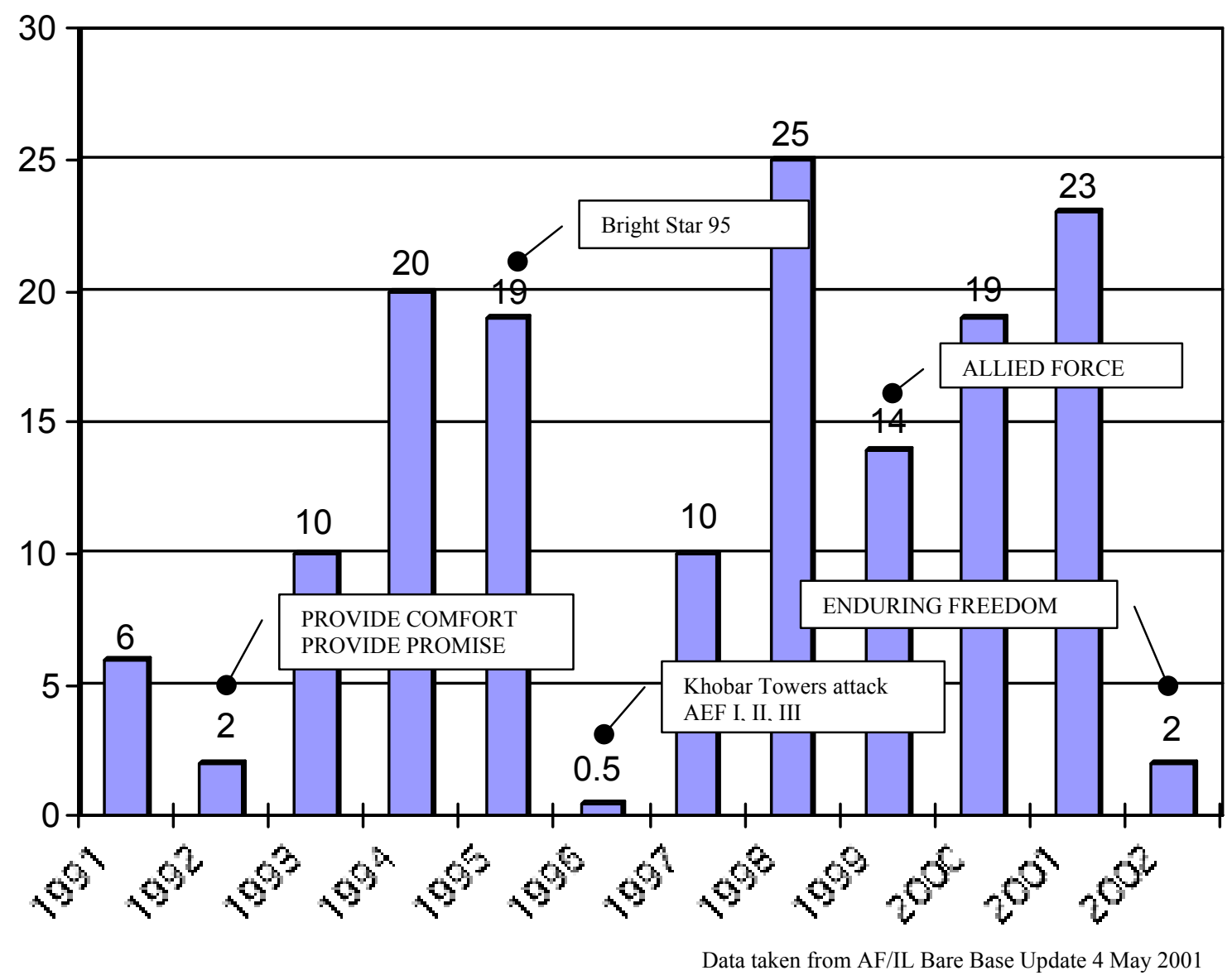

Figure 2. Mission Ready HF Housekeeping Sets

the HF housekeeping sets is shown in Figure 2. After the Gulf War the program was able to get six housekeeping sets mission ready, only to have them pulled for Operations Provide Comfort and Provide Promise, resulting in two mission-ready sets. A 1998 GOA program audit highlighted this trend: 
Since the Persian Gulf War, the Air Force has repeatedly used its bare base sets to support numerous contingencies and exercises. In 1992, bare base equipment was used to support two operations-Joint Endeavor in Bosnia and Provide Comfort in Iraq. In 1996, it was used to support 22 exercises and contingencies, ranging from Dhahran bombing to Operation Desert Strike. ${ }^{23}$

The program was able to recover and build to 20 mission-ready sets when the attack on the Khobar Towers occurred, and bare base equipment was needed to relocate the operation at Dhahran to Prince Sultan Air Base (PSAB). This event again significantly reduced the inventory of available housekeeping sets, which were used for the PSAB tent city until permanent dorms were constructed in late $1997 .^{24}$ When the housekeeping sets were reconstituted in 2000, many were condemned and required additional program funds to replace, illustrating yet another hazard of using bare base equipment intended for temporary use for long-term events. The Air Force's contractor estimated that more than 530 tents could not be reconstituted due to dry rot and general deterioration. ${ }^{25}$ Finally, the program started to make readiness improvements in 1998, only to be called on once again to support Operation Allied Force. Most recently, all but two of the mission-ready housekeeping sets were used to support OEF. ${ }^{26}$

Furthermore, significant problems exist with the way the equipment is treated and operated. An Air Force audit summarized the issue by observing that ". . . equipment from these operations has often been returned in poor condition and has required significant repairs...the Air Force Inspector General noted that prepositioned equipment was generally treated as a disposable, one-time use commodity and that user attitudes had often led to equipment abuses."27 The high usage rate, coupled with the maltreatment and extended use of bare base equipment, has hindered efforts to replace and reconstitute assets fast enough for the program to achieve even a 50-percent mission-ready status just one time in the 12 years shown on the chart. With a stated program requirement to have 50 mission-ready housekeeping sets, the HF program 
maintained just an average of 12.5 mission-ready housekeeping sets, or a 25-percent readiness rate, between 1991 and 2002. The program is in a continual "use-fix-use" ${ }^{28}$ cycle that simply does not allow it to recover. This cycle is further complicated by indirect mission support, which allows the use of bare base assets to support day-to-day events not associated with an exercise or operation.

\section{Indirect Mission Support}

Bare base equipment continues to be used to support the daily Air Force mission and other activities for which it was not intended, a condition referred to as indirect mission support. Between 1996 and 2000, there was an annual average of 120 approved requests but only eight disapproved requests. ${ }^{29}$ The overall impact of indirect mission support has been a decrease in the mission-ready status of bare base sets that the asset is intended to support. For example, in 2001 a mobile aircraft arresting system, a piece of equipment in an industrial set, was loaned to the Royal Saudi Air Force to support fighter operations on an alternative runway while the main runway at Dhahran was under construction. ${ }^{30}$

“In 1998, the Air Force estimated it would take 9 years and cost about $\$ 223$ million to rebuild the Harvest Falcon sets, assuming peacetime use (indirect mission support) is stopped." The use of bare base equipment for indirect mission support further hinders the program's ability to maintain a sufficient amount to support Air Force needs. Another issue concerns recovering costs from the user for the breakout, man-hours, replacement, and reconstitution costs associated with the indirect mission support. At the present time, there are attempts to capture operation and maintenance costs by charging a "rental" fee, ${ }^{32}$ but they fall short of covering the total cost associated with purchasing, storing, and maintaining an asset. Additionally, the Air Force accounting system will not allow the WRM system to charge for procurement funds to replace 
the asset if damage is beyond use when it is returned. Thus, the WRM program element is the bare base program element that is paying the bill when a piece of equipment is used for an exercise, operation, or indirect mission support. Consequently, with each incident of indirect support, the bare base account loses funding, and in the current budgeting process asset replacement normally takes three to five years. ${ }^{33}$ In addition, the indirect mission-support equipment is treated the same as other bare base equipment, increasing the costs to program. A 1998 GAO reported captured the magnitude of the impact of indirect mission support:

Certain key items, such as tents, generators, and air-conditioners, have been used the most and replaced the most frequently. For example, between January 1996 and April 1998, more than 3,000 tents and nearly 4,500 air-conditioning units - about the number required for 27 or 30 complete housekeeping sets, respectively-were deployed from storage locations in Oman and Bahrain to locations throughout the theater. At Prince Sultan Air Base alone, approximately 3,000 air-conditioning units are currently either in use or have been designated as backup units. ${ }^{34}$

The Air Force has considered using commercial sources of equipment to support these requirements but has found the use of bare base assets more cost-effective. For instance, for the 1995 Bright Star exercise the Air Force "calculated that it would cost approximately \$1.7 million to use existing bare base equipment compared to approximately $\$ 10.5$ million ... through a commercial source",35 The problem involves balancing peacetime training with the need to have equipment ready for the next war in a resources-constrained environment. The Air Force may be saving funding to support an exercise, but it is subsidizing the cost of the exercise with the bare base funding account, as well as degrading the readiness of the program.

\section{Funding}

Funding has been and will continue to be the greatest challenge to the program. The bare base program needs an average of $\$ 112.3$ million per year through years FY04-09 to get the 
program healthy and fund the required improvements. Currently the program is short in the FY04-09 POM an average of $\$ 48.6$ million in each year. Specifically, it will require an average of \$35.7 million in procurement annually and \$12.9 million of operations and maintenance funds each year between FY04 and FY09. These amounts are more than the $\$ 278$ million to fix the bare base program by FY09, as shown in Figure 3. The program has a significant bill to pay, with the annual budget being over $\$ 100$ million starting in FY04. ${ }^{36}$

\begin{tabular}{|l|c|c|c|c|c|c|}
\hline \$ in millions & FY04 & FY05 & FY06 & FY07 & FY08 & FY09 \\
\hline Program Funds (3080) & 56.0 & 60.1 & 62.0 & 64.9 & 50.4 & 45.9 \\
\hline Required & 20.7 & 20.1 & 21.0 & 21.2 & 21.2 & 21.2 \\
\hline Programmed in POM & -35.3 & -40.0 & -41.0 & -43.7 & -29.2 & -24.7 \\
\hline Shortfall & \multicolumn{7}{|l|}{} \\
\hline Operations and Maintenance (3400) & 52.8 & 53.5 & 56.8 & 57.1 & 57.1 & 57.1 \\
\hline Required & 44.4 & 43.9 & 44.8 & 45.7 & 45.7 & 45.7 \\
\hline Programmed in POM & -8.4 & -9.6 & -12.0 & -11.4 & -11.4 & -11.4 \\
\hline Shortfall & \multicolumn{7}{|l|}{} \\
\hline Program Totals & 108.8 & 113.6 & 118.8 & 122.0 & 107.5 & 103.0 \\
\hline Required & $\mathbf{- 4 3 . 7}$ & $-\mathbf{- 4 9 . 6}$ & $\mathbf{- 5 3 . 0}$ & $\mathbf{- 5 5 . 1}$ & $\mathbf{- 4 0 . 6}$ & $\mathbf{- 3 6 . 1}$ \\
\hline Shortfall
\end{tabular}

Figure 3. Bare Base Program Element Funding Breakout ${ }^{37}$

It is critical that the Air Force fixes the program now and maintains the capability to rapidly deploy anywhere. If the last 10 years are used to project requirements, the program will spend significantly more than what is budgeted to fix it. The budget is only for replacement of existing equipment and maintenance of equipment in storage and does not include the cost of indirect mission support and maltreatment of equipment. The actual cost is impossible to determine with no estimates being found for this paper. However, a rough estimate can be determined based on the historical data provided. The 1997 Bright Star exercise cost $\$ 1.7$ million and the Air Force supported 22 exercises and deployments in 1996. Both these numbers will be considered the average level of effort for each year to get a rough order of magnitude for exercise and deployment costs. Thus, the rough cost in 1996-97 dollars is $\$ 37.4$ million $(\$ 1.7$ million $\times 22=$ 
$\$ 37.4$ million), or a one-third plus increase in annual costs for just exercise support. The funding impacts of supporting these types of activities can be seen in the supplemental funding that has occurred in recent years in an attempt to get the program back on track. The Department of Defense approved an additional $\$ 71$ million over the next five years to fix some of the bare base programs. The Air Force estimates it will take about nine years and cost about \$223 million to rebuild the Harvest Falcon program. ${ }^{38}$ In addition to this $\$ 72$ million supplement, the program received another $\$ 45.7$ from the Office of the Secretary of Defense in January 1999 (FY00) and subsequently requested another $\$ 30.4$ million supplement to cover the cost of Operation Noble Anvil. ${ }^{39}$

\section{Accounting}

The Air Force considers a set complete if missing components can be airlifted to meet the requirement. "For example, the Air Force has counted 16 housekeeping sets in storage as complete, even though water-distribution systems — an essential housekeeping capability . . . are reported to be stored in the United States. Air Force officials question whether the airlift needed to move these systems to the region would be available during the initial phases of a large-scale conflict. If not, bare base operations could be delayed significantly." ${ }^{40}$ This type of gamesmanship only hurts the credibility of the program and misrepresents actual readiness. The senior Air Force leadership must be able to know there are a certain number of fully missionready sets, without having to ask if all the assets are in the same place and ready to go. Counting generators located at Holloman AFB, New Mexico that will take several days to get to the required location in Oman or the United Arab Emirates is certainly questionable. The program must give accurate status. 


\section{Notes}

${ }^{1}$ Gen Michael E. Ryan, Chief of Staff, US Air Force. Address. The Air Force Association Air Warfare Symposium, Orlando, Florida, 27 February 1998, 3.

${ }^{2}$ US House. Statement of Gen John P Jumper Commander, United States Air Forces in Europe, United States Air Force [Online] Available: http://www.house.gov/hasc/testimony/106thcongress/99-10-26jumper.htm,

26 October 1999, 8.

${ }^{3}$ Feinberg et al., xvi-xvii.

${ }^{4}$ Jumper.

5 Robert S. Tripp, et al., "Supporting Aerospace Expeditionary Forces: Lessons from the Air War Over Afghanistan," RAND Draft report, 64.

${ }^{6}$ Ibid. 65.

${ }^{7}$ Ibid. 73

8 Robert S. Tripp, et al., "Supporting Aerospace Expeditionary Forces: An Integrated Strateic Agile Combat Support Planning Framework." RAND MR-1056-AF, 1999, 63.

9 Robert S. Tripp, et al., "Supporting Aerospace Expeditionary Forces: Lessons from the Air War Over Afghanistan," RAND Draft report, 120-121.

${ }^{10}$ Headquarters United States Air Force. Briefing. "Bare Base Systems Status Update Harvest Falcon and Harvest Eagle" [Online] Available: http://140.185.52.73/ilx/ilxx/wrm/index.html, 4 May 2001, slide 18.

11 "Bare Base Systems Status Update--Harvest Falcon and Harvest Eagle," 23-24.

${ }^{12}$ T Robert S. Tripp, et al., "Supporting Aerospace Expeditionary Forces: Lessons from the Air War Over Afghanistan," RAND Draft report, 120.

13 "Bare Base Systems Status Update--Harvest Falcon and Harvest Eagle," 53-56

${ }^{14}$ ECUs are air-conditioning units used to cool and heat tents and workspaces.

15 "Bare Base Systems Status Update--Harvest Falcon and Harvest Eagle," 53-56.

${ }^{16}$ Ibid. 53.

17 US GAO. "Military Prepositioning: Army and Air Force Programs Need to be Reassessed.” GAO/NSIAD-99-6 November 1998, 41.

18 "Military Prepositioning: Army and Air Force Programs Need to be Reassessed," p. 42.

${ }^{19}$ Ibid. 41.

${ }^{20}$ Air Force Audit Agency. "Bare Base Mobility Program (Harvest Bare)," 10 September 1973, 4.

21 "Bare Base Mobility Program (Harvest Bare)," 17-18.

${ }^{22}$ Minutes. "Force Modules and BEAR Capability." Holloman AFB, 19-21 November 2002, $1-12$.

23 "Military Prepositioning: Army and Air Force Programs Need to be Reassessed." 46.

${ }^{24}$ Ibid. 48.

${ }^{25}$ Ibid.

${ }^{26}$ Robert S. Tripp, et al., "Supporting Aerospace Expeditionary Forces: Lessons from the Air War Over Afghanistan," RAND Draft report, 120.

${ }^{27}$ Worldwide War Reserve Materiel, Air Force Inspector General Documented Briefing, PN 97-701, 8 June 1996.

28 "Bare Base Systems Status Update--Harvest Falcon and Harvest Eagle," 10.

${ }^{29}$ Ibid. 6-8

${ }^{30}$ JTF-SWA/J4 e-mail March 2001. 


\section{Notes}

31 "Military Prepositioning: Army and Air Force Programs Need to be Reassessed," 43.

32 "Bare Base Systems Status Update--Harvest Falcon and Harvest Eagle," 35.

${ }^{33}$ Lt Col Tom Huber, AF/ILSR briefing. "Future Funding for the Bare Base Program: The Iceberg Effect" [Online] Available: http://140.185.52.73/ilx/ilxx/wrm/afwerb achive.html. September 2000, 5 .

34 "Military Prepositioning: Army and Air Force Programs Need to be Reassessed," 46.

${ }^{35}$ Ibid. 48.

36 "Bare Base Systems Status Update--Harvest Falcon and Harvest Eagle," 44.

${ }^{37}$ Ibid

38 "Military Prepositioning: Army and Air Force Programs Need to be Reassessed." 43.

${ }^{39}$ Major Hai Vu, 23.

40 "Military Prepositioning: Army and Air Force Programs Need to be Reassessed," 44. 


\section{Will the Bare Base Program be There When Needed?}

The Chief of Staff is developing force modules to provide improved capabilities for rapidly opening an airfield or generating the needed number of fighter and bomber sorties anywhere in the world. These force modules include initial airbase establishment, command and control, mission generation, and airbase operations activities. This next step in the expeditionary journey will require a strong bare base program as its foundation. But is the bare base program capable of supporting this level of effort? Based on the data provided in this paper, indications are that the task will be a challenging one. The program has not been able to recover since the end of the Gulf War, with the best mission-readiness status topping out at 50 percent in 1998 and the average readiness rate hovering around 25 percent. During this period there was simply not enough bare base equipment mission ready to support a major conflict or, in the worse case, two major theater wars in two or more regions. Based on the projected funding, continued indirect mission support, and high usage rate, there can be no reasonable scenario to indicate that the mission-ready status can exceed the last 10-year average of 12.5 housekeeping sets in the next 5 to 10 years. In 1996 the HF program's ability to field just one housekeeping set got the attention

of the Chief of Staff, who identified several problem areas and directed AF/IL to fix them. ${ }^{1}$ The $\mathrm{AF} / \mathrm{IL}$ made changes to remedy program deficiencies and estimated then that several years would be required to get the program healthy.

The need to have bare base assets is widely understood among some Air Force leaders. As General John W. Handy stated in his Congressional testimony following Operation Allied Force: "Rapid reconstitution following operations plays a key role in maintaining the readiness of the USAF to reengage for future conflicts. As this committee is fully aware, we need to 're-load' 
our resources of munitions, spares, and equipment expended during Allied Force to ensure we have the capability to meet the next contingency ....." Unfortunately, General Handy overlooked the fact that the bare base program had less than 50 percent of the required housekeeping sets before the start of Allied Force. Should not the Air Force have all the funds needed to get the program healthy, rather than just a portion? The use-fix-use cycle is difficult enough to manage and is even more difficult when the program is unhealthy from the start. Surprisingly, more of the senior leadership is not aware of the challenges faced in the bare base programs. Referring to OEF, the Air Force Director of Plans was "surprised to the extent combat support resources were stressed in an operation where the Air Force pushed very little iron forward." 3 One of the major challenges in OEF was getting the limited bare base assets to the right place in a timely manner and then having to piece together the remaining parts of sets to provide the required support.

The Air Force began OEF with 28 housekeeping sets on hand, and the operation utilized only five percent of the fleet. ${ }^{4}$ Seventeen HF housekeeping sets were fully mission-ready, and 15 of these were used to set up the OEF airbases. Two sets were kept in reserve, while the 11 remaining HF housekeeping sets were pieced together to provide varying degrees of support throughout the OEF region. ${ }^{5}$ Consequently, the Air Force now has only enough housekeeping sets in the area of responsibility to bed down an additional 2,200 people. Further before the process of building additional set can begin, several thousand items must be purchased for the sets that are being reconstituted. Prior to the start of OEF, the HF sets required the purchase of 12,457 major components to rebuild them. This number will significantly grow as a result of OEF using all the HFs except two. Moreover, the program element from which these funds will come to buy the assets is already underfunded by $\$ 35.6$ million each year in the FY04-09 POM. 
If another conflict erupts in the Middle East or OEF expands, the Air Force will need to seek alternative methods to establish an airbase at bare base locations. Options such as using the HE assets or requesting the Army Force Provider ${ }^{6}$ assets exist, but these options degrade the Pacific theater HE readiness. Because any conflict will eventually draw upon Army support, the Army probably would not be able to lend the required support. As a result, without significant funding the bare base program is not capable of providing support today or in the future to the full extent required.

The $e$-Falcon and BEAR initiatives do nothing more than reconfigure the HF and HE sets into a number of smaller packages that can be moved quickly. The entire HF and HE sets will still be needed as the airbase matures and operations tempos increase. The fact remains, current theater operations plans require $53 \mathrm{HF}$ housekeeping sets, $16 \mathrm{HF}$ industrial sets, $35 \mathrm{HF}$ flight line sets, 24 HE housekeeping sets, and 13 T-550 housekeeping sets. ${ }^{7}$ Indeed, the Air Force has been able to keep less than 50 percent of these 141 sets mission-ready between 1991 and 2002. Other than request supplemental funding and attempt to increase the program out-year budget, what can the Air Force do to enhance mission readiness?

For one thing, the established requirements for the bare base program need to be revalidated. This author could not find a solid methodology for determining requirements to set up an airbase at a bare base location. The existing operations plan requirements have been established using historical information rather than sound analysis, and without some analysis, the program will always be plagued with doubts about the number of sets needed. Although these requirements have not been adjusted in more than 20 years, the world has changed significantly, especially the spectrum of conflict across which the Air Force is now expected to operate. The Joint Chiefs of Staff Chairman's draft National Military Strategy (NMS) emphasizes that "maintaining the 
strategic ability necessary to respond to unanticipated threats, even while conducting simultaneous operations in widely dispersed operations" ${ }^{\prime 8}$, is essential to the US military's ability to conduct rapid decisive operations.

Clearly the most significant impact to the long-term health of the bare base assets is the continual support of indirect missions events that are big contributors to the debilitating use-fixuse cycle. A reasonable estimate is that indirect mission support costs the program tens of millions of dollars each year. The program was justified on supporting wartime requirements, not indirect mission support. Program mission readiness is further degraded with the maltreatment of equipment when it is used, which drives replacement and repair costs even higher. During the FY04-09 POM cycle, the bare base program is facing a \$278 million shortfall that must be funded for the Air Force to be able to take the next step in its expeditionary journey. But funding is not a permanent fix. The entire program must be reassessed from requirements development to indirect mission-support policies. It cannot continue to operate as it has since the end of the Gulf War. The last 12 years of performance should be all that is needed for the Air Force to recognize a change is needed. The program today is using all but two HF housekeeping sets to support a small operation in Southwest Asia, and with the threat of an expanded war with Iraq, the Air Force will need to use HE sets. Moreover, the United States now faces an increasing possibility of a conflict in the Pacific. Obviously, not enough mission-ready sets are available right now, let alone to support one or more conflicts.

\section{Notes}

${ }^{1}$ Reassessed." GAO/NSIAD-99-6 November 1998, 48.

1 "Bare Base Systems Status Update--Harvest Falcon and Harvest Eagle," 28.

${ }^{2}$ US House. Statement of Lt Gen John W. Handy, USAF Deputy Chief of Staff/Installations and Logistics, United States Air Force [Online] Available: http://www.house.gov/hasc/testimony/106thcongress/99-10-26handy.htm, 26 October 1999, 5. 


\section{Notes}

${ }^{3}$ Robert S. Tripp, et al., "Supporting Aerospace Expeditionary Forces: Lessons from the Air War Over Afghanistan," RAND Draft report, 72.

4 Ibid. 120.

5 Ibid. 120.

${ }^{6}$ Force Provider is the Army equivalent to the Air Force bare base program.

7 "Bare Base Systems Status Update--Harvest Falcon and Harvest Eagle."

${ }^{8}$ CJCS Pre-Decisional Draft, "National Military Strategy, 9 August 2002, 6. 


\section{What Does the Air Force Need to Fix?}

The draft NMS discussion of risk management sums up the situation facing the Air Force's bare base program:

Assessing risk begins with the articulation of a core military requirement against which existing and projected capabilities can be measured. A core military requirement is a broad, unconstrained expression of what the Joint Force must be able to do to execute this strategy. With unlimited resources, meeting the core military requirement can be accomplished at low to negligible military risk as success is virtually assured. However, when resources are constrained, choices must be made and levels of risk assessed and accepted before military operations are undertaken. ${ }^{1}$

Bare base requirements have been established in the unconstrained environment, and through the budget process, the Air Force has made choices and accepted a level of risk for the bare base program. Is this level of risk acceptable? With two congressional supplemental appropriations and a request for a third to keep the program alive, allocating and appropriating \$278 million in the budget to fix this program is highly unlikely. Despite an average less than 50-percent mission-readiness rate over the last 12 years, the Air Force was still able to support most conflicts it faced. Such was the case in OEF as the program was able to use pieces of 11 unserviceable sets to provide basic support.

The Air Force leadership clearly comprehends the importance of the bare base program for expeditionary operations and realizes that inadequate funding levels gradually degrade capability, reduce supportability, and increase repair and reconstitution costs. ${ }^{2}$ Because increased funding is unlikely, the Air Force must consider other ways to increase readiness and reduce costs. In a defense budget in which bare base assets must compete with aircraft spares and new weapon systems like the F/A-22, what can be done to mitigate the program's shortfalls? While new technology to ease setup and tear down will help, the program's largest challenge is 
in the management of existing assets. Therefore, the following recommendations are made to improve the readiness status of the bare base program.

First, AF/IL must issue policy stopping indirect mission support of HF and HE assets, a practice that perpetuates the use-fix-use cycle. By subsidizing every exercise and deployment that plans to use the bare base assets but does not plan to pay for their replacement or reconstitution, this support costs the program millions of dollars each year. Completely stopping the indirect mission support of HF and HE will be difficult to implement. The Air Force has become accustom to using the assets when required or desired. But every reduction in peacetime use can free up for critically needed funds to reconstitute other sets.

Second, the program must charge all customers for the cost of using the equipment in every event. The program is established based on wartime requirements, as identified in the operations plans. As a normal course of "reloading" after a conflict, the cost of reconstituting the equipment and getting it ready for the next conflict should be standard operating procedures. The program should be able to charge to maintain, store, and issue equipment as required, but, in contrast to what has occurred after every operation in the last decade, it should not bear the burden of using these funds to reconstitute and replace equipment.

Third, maltreatment of equipment must cease. Such abuse is a squadron and wing level leadership issue and is totally inexcusable. Though the program has management and accountability policies, no one seems to own the equipment once it goes to the field. The Air Force must change its throwaway mindset regarding bare base assets and must hold units accountable when wrong doing is found. 
The decades-old requirement must be revalidated. AF/IL in conjunction with Air Force materiel Command, must develop methodologies or formulas to determine the right amount of equipment required to set up an airbase at a bare base location today and in the near future.

Finally, research and development is primarily focused on lighter and stronger equipment, faster setup, and better maintainability but not on what is needed to support an F/A-22 or B-2 type aircraft. Given acquisition and development lead times, fielding these items prior to 2010 is unlikely and not possible without immediate POM funding.

\title{
Notes
}

\author{
${ }^{1}$ Ibid. 9. \\ ${ }^{2}$ Huber, 10.
}




\section{Conclusion}

The future security environment will require the Air Force to be even more flexible. According to the new NMS, the key to being able to employ and sustain forces anywhere ". . . is the ability to quickly transition from one type of operation to another or between phases of an operation. This concept allows US forces to conduct and sustain multiple simultaneous missions

in the geographically separated and environmentally diverse regions of the world". The current readiness of bare base assets is certainly incapable of supporting the USAF Chief of Staff's and the Chairman's vision of global expeditionary operations. The solutions recommended in this paper must be implemented at once for the Air Force to be a truly expeditionary force in the $21^{\text {st }}$ century.

\section{Notes}

${ }^{1}$ CJCS Pre-Decisional Draft, "National Military Strategy, 9 August 2002, 8. 


\section{Bibliography}

Air Force Audit Agency. "Bare Base Mobility Program (Harvest Bare)," 10 September 1973.

Air Force Handbook (AFH) 10-222. "Guide to Bare Base Assets," 1 December 1996.

Air Force Inspector General. "Worldwide War Reserve Materiel," Air Force Inspector General Documented Briefing, PN 97-701, 8 June 1996.

AFRL/ML. "AFRL/ML Success Story: Inflatable Structures Can Reduce Logistics and Setup Times for Bare-base Operations" [Online] Available: http://www.ml.afrl.af.mil/stories/ mlq-01124.html.

Aular, Raimundo J. et al. "The Evolution and Role of the Bare Base Concept and Equipment in a Modern Tactical Air Mobility Environment." Thesis SLSR-11-74B, Air Force Institute of Technology (AU), Wright-Patterson AFB, Ohio, August 1974.

CJCS Pre-Decisional Draft, “National Military Strategy,” 9 August 2002.

Dowdy, William L. "Testing the Aerospace Expeditionary Force Concept: An Analysis of AEFs I - IV (1995-97) and the Way Ahead.” Research paper 2000-01. Airpower Research Institute, College of Aerospace Doctrine, Air University, Maxwell AFB, Alabama.

Feinberg, Amatzia, et al. "Supporting Expeditionary Aerospace Forces: Lessons from the Air War Over Serbia," RAND, MR-1263-AF, 2002.

Gabicke, Mark E. "Military Propositioning: Army and Air Force Programs Need to Be Reassessed." United States General Accounting Office. GAO/NSIAD-99-6. Washington DC, November 1998.

Galluzzi, James R. "The Bare Base Program--History and Analysis." Research Study. Air Command and Staff College, Maxwell AFB, Alabama, May 1974.

Vu, Major Hai. ACC/LGXW briefing. "Harvest Eagle - Harvest Falcon United States Air Force Bare Base Systems" [Online] Available: http://140.185.52.73/ilx/ilxx/wrm/ wrmworkshop11.ppt, 22 June 1999.

Huber, Lt Col Tom. AF/ILSR briefing. "Future Funding for the Bare Base Program: The Iceberg Effect" [Online] Available: http://140.185.52.73/ilx/ilxx/wrm/ afwerb achive.html, September 2000. 
Headquarters Air Combat Command. "Mission Needs Statement for Air Force Bare Base Systems.” CAF 316-92. Langley AFB, Virginia, 15 February 1994.

Headquarters United States Air Force. Briefing. "Bare Base Systems Status Update - Harvest Falcon and Harvest Eagle" [Online] Available: http://140.185.52.73/ilx/ilxx/wrm/ index.html, 4 May 2001.

Headquarters United States Air Force. "Program Management Directive for Mobile Bare Base Equipment.” Washington D.C. PMD 2054 (9) PE 0208031F, 27 March 1998.

Headquarters United States Air Force. "RDTE \& E Budget Item Justification Sheet (R-2A Exhibit): 03-Advanced technology Development, 0603205F Flight Vehicle Technology" Washington D.C. February 2002.

Jumper, General John P. “Chief’s Sight Picture: Corona Fall 2002,” 22 October 2002.

Kautz, Lt Col James G. “Takhli, RTAFB, May 1972, The First Ten Days.” Case Study. Air War College, Maxwell AFB, Alabama, April 1974.

Killingsworth, Paul S. et al. "Flexbasing: Achieving Global Presence for Expeditionary Aerospace Forces," Washington D.C. RAND, MR-1113-AF, 2000.

Minutes. "Force Modules and BEAR Capability." Holloman AFB, New Mexico, 19-21 November 2002.

Minutes. "Air Force 1987 Worldwide WRM Conference." USAF/LEXX, Wright-Patterson AFB, Ohio, 1987.

Neef, Paul A. et al. "War Materiel Capability Assessment (WRM-CA)." United States Air Force Research Laboratory. AFRL-HE-WP-TR-2002-0103. Wright-Patterson AFB, Ohio, May 2001.

United States General Accounting Office. "Military Prepositioning: Army and Air Force Programs Need to Be Reassessed." Washington D.C. GAO/NSIAD-99-6, November 1998.

US House. Statement of: General John P. Jumper Commander, United States Air Forces in Europe, United States Air Force. [Online] Available: http://www.house.gov/hasc/ testimony/106thcongress/99-10-26jumper.htm, 26 October 1999.

US House. Statement of: Lieutenant General John W. Handy, USAF Deputy Chief of Staff/Installations and Logistics, United States Air Force. [Online] Available: http://www.house.gov/hasc/testimony/106thcongress/99-10-26handy.htm, 26 October 1999. 
Ryan, General Michael E., chief of staff, US Air Force. Address. The Air Force Association Air Warfare Symposium, Orlando, FL., 27 February 1998.

Report. "RDT\&E Budget Item Justification Sheet (R-2A Exhibit) for 03--Advanced Technology Development." PE 0603205F Flight Vehicle Technology 34398, February 2002.

Tripp, Robert S., et al. Supporting Aerospace Expeditionary Forces: Lessons from the Air War Over Afghanistan. Washington D.C. RAND draft report 2002.

Tripp, Robert S., et al. Supporting Expeditionary Aerospace Forces: An Integrated Strategic Agile Combat Support Planning Framework. Washington D.C. RAND MR-1056-AF, 1999.

Weaver, Captain Kenneth M. "An Historical Analysis of the Air Force's Bare Base Concept and Equipment." Thesis. AFIT/GEM/LSR/895-18, Air Force Institute of Technology, Wright-Patterson AFB, Ohio, 28 December 1989. 